\title{
THE USE OF PANCREATIC EXTRACT AS A GROWTH STIMULANT FOR G. DIPHTHERIAE
}

\author{
BY \\ M. GORDON AND K. ZINNEMANN \\ From the Department of Pathology and Bacteriology, University of Leeds
}

(RECEIVED FOR PUBLICATION, APRIL 13, 1949)

Gordon (1945), investigating the influence of various components of serum on the growth of C. diphtheriae, used pancreatic extract (liq. trypsin co.) and extract of gastric mucous membrane (" pepsin") to prepare serum digests. He found that these extracts themselves, particularly the former, had a markedly stimulating effect on the growth of $C$.diphtheriae and that they retained this power even after the digestive enzyme content had been inactivated by heat. The active principle in the pancreatic extract is water-soluble, passes readily through a collodion membrane, and is thus of low molecular weight.

Further investigations were undertaken to determine whether pancreatic extract could with any advantage be incorporated in some of the blood tellurite media commonly used for the isolation of $C$. diphtheriae. The heated blood tellurite agar of Anderson et al. (1931) prepared with low temperature meat extract gives excellent type differentiation but is at a disadvantage when certain haematin-sensitive mitis and gravis strains (Glass, 1937 ; Robertson, 1943) are encountered. This difficulty is overcome by using unheated instead of heated blood (Glass, 1937). Hoyle's (1941) tellurite medium, though not suggested specially for haematin-sensitive strains, permits their growth as it contains lysed unheated blood in a Lemco agar plate. Hoyle claimed rapidity of diagnosis but admitted that type differentiation was inferior to that on McLeod's medium. Johnstone and Zinnemann (1943) used an unheated blood tellurite mixture and low temperature meat extract, and showed that the low temperature meat extract in McLeod's medium is largely responsible for good type differentiation. Hoyle's medium was very much improved by the substitution of low temperature meat extract for Lab. Lemco broth, and Johnstone and Zinnemann's medium prepared with Lab. Lemco broth produced growth little better than that on Hoyle's original medium. The preparation of low temperature meat extract involves a somewhat complicated technique and may prove of considerable difficulty under certain conditions. It was thought that the addition of pancreatic extract to blood tellurite media might prove a useful substitute for low temperature meat extract.

\section{Method}

The pancreatic extract chiefly used for its trypsin content was liq. trypsin co. It is made by extracting pancreatic glands with dilute alcohol acidified with phosphoric acid. The trypsin-containing-fraction is precipitated from this solution by alcohol and is then dissolved in $1 \%$ phosphoric acid, and an equal volume of glycerine is added to obtain a product of a more or less constant trypsin content. A pancreatic extract made for us without glycerine being added, and one made in the laboratory by the method described for the preparation oî Hartley's broth (Mackie and McCartney, 1948) gave equally satisfactory results. Pancreatic extracts may vary in strength compared with liq. trypsin co., and the optimum concentration for incorporation in the medium varies accordingly. Before use the liq. trypsin co. was adjusted to $p \mathrm{H} 7.6$ and boiled for five minutes to sterilize and incidentally inactivate the digestive enzyme fraction. Some reduction in the growth-promoting properties of the extract occurred if it were sterilized by autoclaving, but it still remained quite potent. A slight precipitate appeared on boiling the extract, and as its removal also resulted in some diminution of growth-stimulating properties the precipitate was retained. The boiled extract was added to the media to be investigated just before pouring.

The cultures of $C$. diphtheriae used were a number of stock gravis, mitis, and intermedius strains showing the typical characteristics described by McLeod (1943), and also some haematin-sensitive strains.

Results of the Experiments. - One to $10 \%$ boiled liq. trypsin co. adjusted to $p \mathrm{H} 7.6$ was added to (1) unheated lysed blood tellurite agar with Lab. Lemco base (Hoyle); (2) heated blood tellurite agar (McLeod); 
(3) a medium made with unheated blood tellurite mixture (Johnstone and Zinnemann). Media Nos. 2 and 3 were prepared both with Wright's broth (1933) and with low temperature meat extract. On all media reinforced with certain concentrations of pancreatic extract $C$. diphtheriae colonies showed markedly increased growth, particularly as regards the size and depth of single colonies. This was especially noted with gravis and mitis strains. The concentrations of pancreatic extract required to produce the optimum effect varied with the different media and appeared to be related to the presence or absence of unheated blood and also particularly to the presence of low temperature meat extract (see Table).

TABLE

\begin{tabular}{|c|c|}
\hline Medium & $\begin{array}{c}\text { Optimum } \\
\text { Concentration } \\
\text { of Pancreatic } \\
\text { Extract }(\%)\end{array}$ \\
\hline $\begin{array}{l}\text { Heated blood tellurite agar prepared } \\
\text { with Wright's broth }\end{array}$ & $\begin{array}{l}5.0 \\
2.5 \\
2.5 \\
1.0\end{array}$ \\
\hline
\end{tabular}

Any marked addition of pancreatic extract above these percentages may have an inhibitory effect and produce smaller gravis and mitis colonies, though intermedius colonies do not appear to be so much affected.

The increase of the size of the colony on blood tellurite media containing pancreatic extract was also associated with better type differentiation, and this was particularly striking on media, such as Hoyle's, prepared without low temperature meat extract. On the latter the differentiation between gravis and mitis strains may be confusing, as mitis colonies often appear rougher and duller, and gravis colonies smoother, than on other media. The addition of pancreatic extract to the medium promotes a smoother and shinier mitis colony and at the same time emphasizes the dullness and roughness of gravis colonies (see Figs. 1-6). Also pancreatic extract further emphasizes type characteristics even on media prepared with low temperature broth, producing round, shiny, confluent mitis and daisy-head gravis colonies.

Pancreatic extract has no influence in promoting growth of haematin-sensitive strains of $C$. diphtheriac on heated blood media, but when it is incorporated in media permitting their growth it has a stimulating effect, though somewhat less than on normal gravis and mitis strains.

The effect of the incorporation of pancreatic extract in blood tellurite media on other organisms frequently encountered is obviously of some importance, as any marked stimulation of their growth may nullify its advantage in the recognition of $C$. diphtheriae from routine throat swabs. Culture plates of Hoyle's medium containing up to $5 \%$ of boiled liq. trypsin co. were inoculated with strains of $C$. hofmanni, $B$. subtilis, streptococci, $H$. influenzae, and yeast. of these $C$. hofmanni, streptococci, and $B$. subtilis showed a slight increase in the size of the colony, though much less than the increase of $C$. diphtheriae colonies. B. subtilis colonies also presented a more mucoid appearance but showed no tendency to spread. The slightly stimulating effect on these contaminants was probably due to the glycerine content of liq. trypsin co., as it did not occur if a glycerine-free pancreatic extract was used.

Cantani in 1910 found that $C$. diphtheriae grew exceedingly well on a glycerine blood agar medium. This fact was later made use of by Clauberg (1935-6), i and his Media II and III contain a proportion of $\varnothing$ glycerine (1933). Our further experiments showed that the glycerine content of liq. trypsin co. played no appreciable part in the stimulating effect on the growth of $C$. diphtheriae, and this appeared to be due solely to the pancreatic extract.

The addition of $5 \%$ pancreatic extract to Wright's nutrient broth also had a stimulating effect on growth of $C$. diphtheriae, with emphasis on type characteristics. Thus, of 16 stock gravis strains which during subculture over several years had lost the capacity to form pellicles on Wright's broth, nine showed typical coarse gravis pellicles when grown in this medium reinforced with pancreatic extract. Mitis strains grown in it exhibited a surface ring of bacterial growth adherent to the wall of the test tube, a characteristic first described by Hettche $(1935 ; 1935-6)$. Some mitis strains occasionally developed pellicles, but these were soft, quite unlike gravis pellicles, and on shaking the test tube a uniform turbidity was produced in contrast to the coarse, floccular deposit from gravis pellicles.

\section{Discussion}

Certain workers abroad report difficulties in placing a considerable number of their $C$. diphtheriae strains within the three main types described by McLeod (1943). Although this may be due in part to the peculiarities of these strains, it is possible that the absence of low temperature broth in the tellurite media is partly responsible. It is an interesting speculation whether the active principles in low temperature broth and in pancreatic extract are similar and, if so, whether these are also present in other tissues. An effect similar to that of pancreatic extract is obtained with extract of gastric mucous membrane, and it is noteworthy that Gordon (1945) also reported the presence of a potent growth stimulant for gravis and mitis strains of $C$. diphtheriae in an aqueous extract of yeast. Recently a growth factor for Gram-positive bacteria has been described by Darzins (1948), though its characteristics do 
not suggest that this factor is identical with the principle active in pancreatic extract.

As the growth-stimulating substance in pancreatic extract is still active after the tryptic enzyme has been destroyed by heat, the effect here described is not comparable to that in media such as Hartley's broth (1922), the preparation of which depends on active tryptic digestion. Pancreatic extract in the form of active trypsin was used in tellurite media containing serum by Douglas (1922) and Allison and Ayling (1929) for the purpose of neutralizing an antitryptic power of serum postulated by A. E. Wright (1915). In the light of the present observation the improved growth observed on these media may in part have been due to the heat-stable component of pancreatic extract rather than to the effect ascribed to the tryptic enzyme.

Owing to the present exceedingly low incidence of clinical diphtheria in the Leeds area it has not been possible to test tellurite media containing pancreatic extract in the routine examination of swabs, - but the experimental results obtained seem to indicate its use being well worth a trial especially where low temperature broth media are not available.

Apart from its uses in bacteriological diagnosis pancreatic extract may be of importance in the production of $C$. diphther:ae toxin, as the latter is to some degree dependent on the extent of pellicle formation which, as shown, is stimulated by pancreatic extract.

\section{Summary}

Extract of pancreas as prepared for use in tryptic digestion contains a thermostable component which markedly stimulates growth and also emphasizes colonial type characteristics of $C$. diphtheriae.

Maximum stimulation of both growth and type characteristics is dependent on an optimum concentration of pancreatic extract.

The incorporation of pancreatic extract in tellurite media is of practical value for the isolation and typing of $C$. diphtheriae. Contaminants usually present in throat and nasal swabs are not stimulated to any extent.

Acknowledgments are due to Mr. A. Myers for technical assistance, and to Mr. J. Hainsworth for the photographs.

\section{REFERENCES}

Allison, V. D., and Ayling, T. H. (1929). J. Path. Bact., 32, 299 Anderson, J. S., Happold, F. C., McLeod, J. W., and Thomson, J. G. (1931). J. Path. Bact., 34, 667.

Cantani A. (1910). Zbl. Bakt., I. Orig., 53, 471.

Clauberg, K. W. (1933). Zbl. Bakt., I. Orig., 128, 153.

Clauberg, K. W. (1935 6). Zbl. Bakt., I. Orig., 135529.

Da'zins, E. (1948). Z. Hig. Infektkr., 128, 662 .

Douglas, S. R. (1922). Brit. J. exp. Path., 3, 263.

Glass, V. (1937). J. Path. Bact., 44, 235.

Gordon, M. (1945). M.D. Thesis. School of Medicine, Leeds.

Hartley, P., and Hartley, O. M. (1922). J. Path. Bact., 25, 458.

Hettche, H. O. (1935). Zbl. Bakt., I. Orig., 134, 421.

Hettche, H. O. (1935-6). Z. Hyg. Infektkr., 117, 33.

Hettche, H. O. (1935-6). Z. Hyg.
Hoyle, L. (1941). Lancet, 1, 175 .

Johnstone, K. I., and Zinnemann, K. (1943). J. Path. Bact, 55, 53. Mackie, T. J., and McCartney, J. E. (1948). “ Handbook of Practical Bacteriology." 8th Edit. (Edinburgh). P. 146.

McLeod, J. W. (1943). Bact. Rev., 7, 1.

Robertson, D. H. (1943). M.D. Thesis. University of St. Andrews.

Wright, A. E. (1915). Brit. med. J., 2, 629.

Wright, H. D. (1933). J. Path. Bact., 37, 257. 


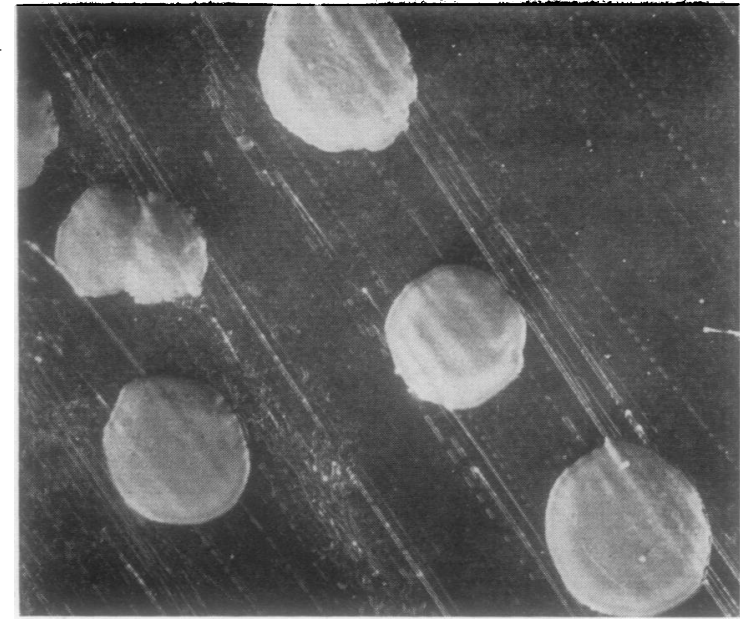

FIG. 1. - C. diphtheriae gravis on Hoyle's medium. $\times 14.2$. Strain $577 / 7$ incubated for 48 hours.

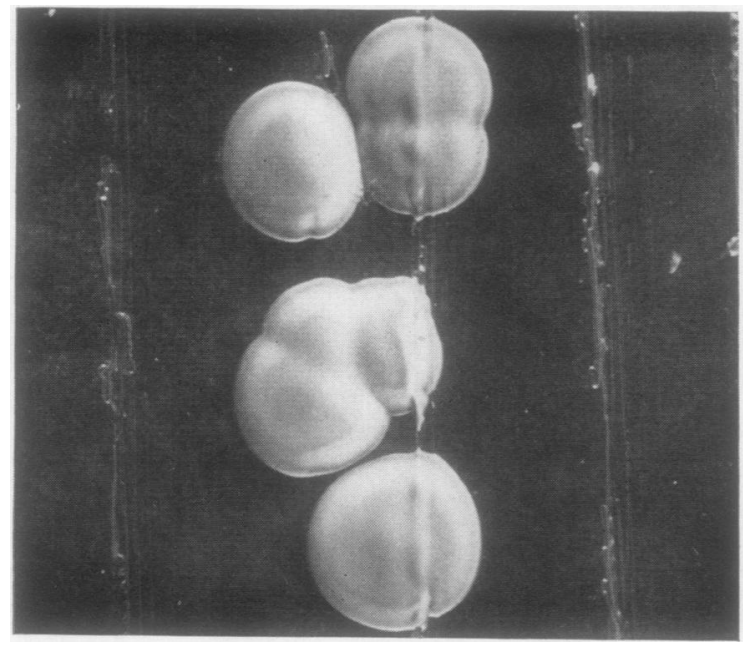

FIg. 3. -C. diphtheriae mitis on Hoyle's medium. \× 14.2 . Strain Y 523 incubated for 48 hours.

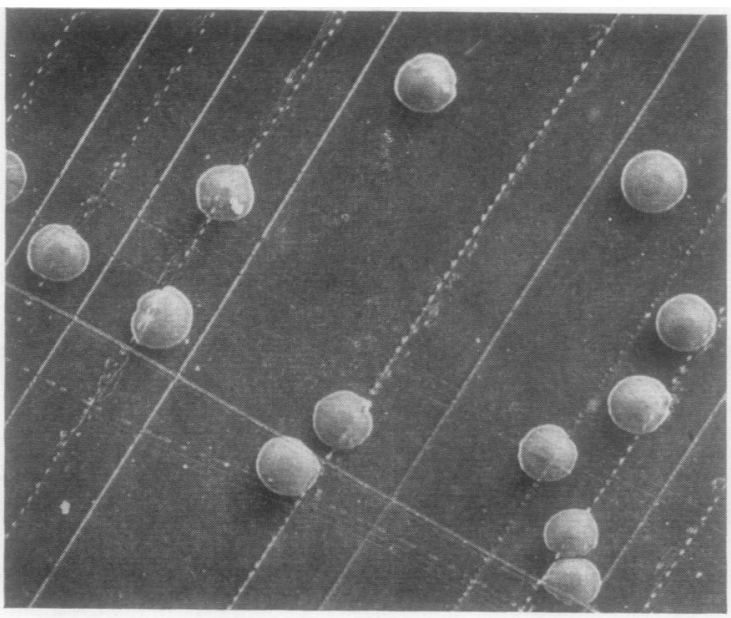

FIG. 5. - C. diphtheriae intermedius on Hoyle's medium. $\times$ 14.2. Strain 214 incubated for 48 hours.

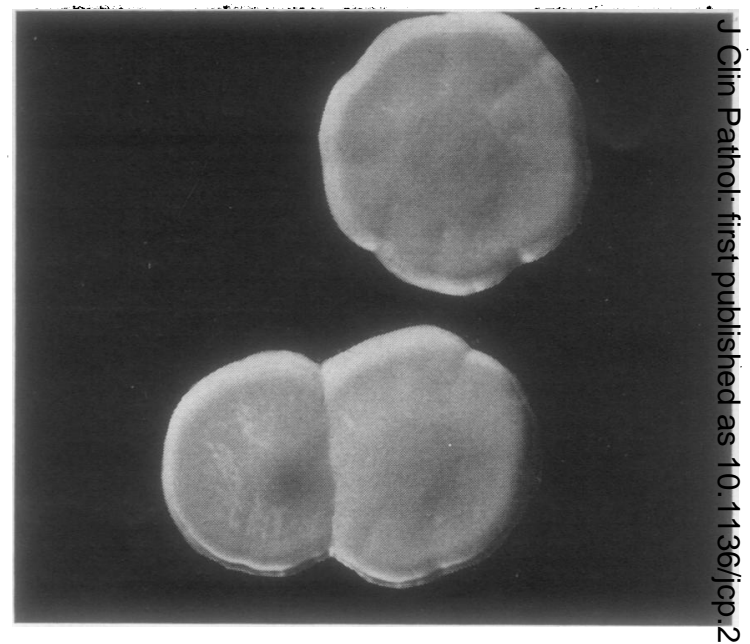

FIG. 2.-C. diphtheriae gravis on Hoyle's medium $+2.5^{\circ} \%$ pancreatic extract. $\times 14.2$. Strain $577 / 5$ incubated for 48 hours.

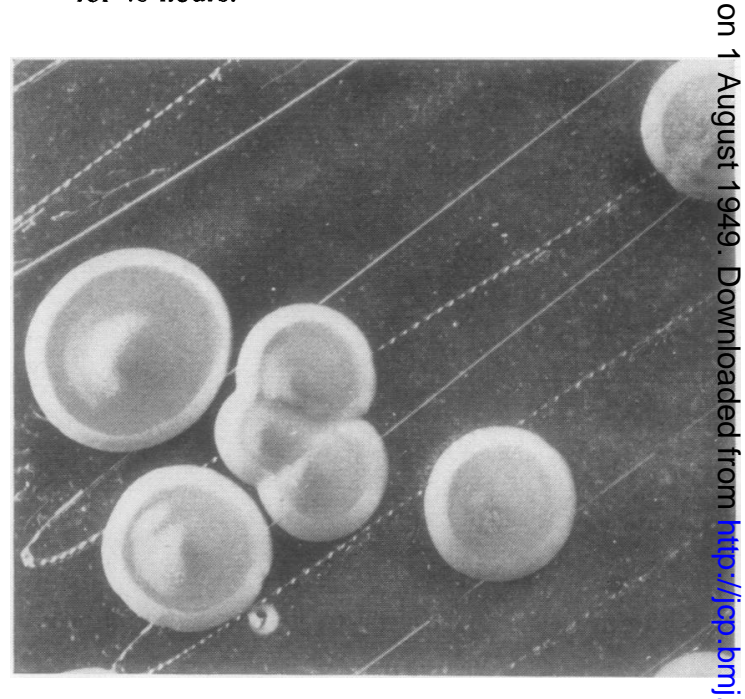

FIG. 4.-C. diphtheriae mitis on Hoyle's medium $+2.5 \%$ pancreatic extract. $\times 14.2$. Strain Y 523 incubate for 48 hours.

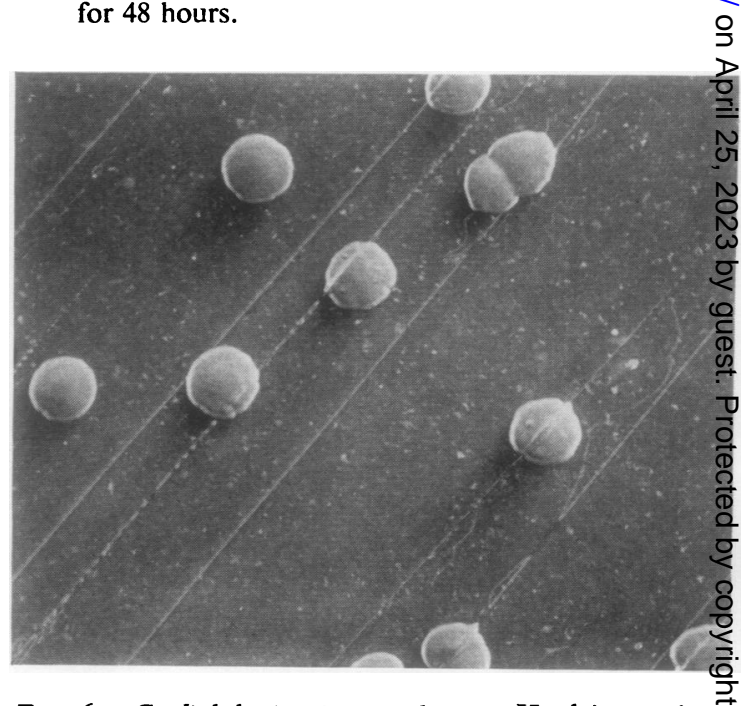

FIG. 6.-C. diphtheriae intermedius on Hoyle's medium $+2.5 \%$ pancreatic extract. $\times 14.2$. Strain 214 incubated for 48 hours. 